\title{
PEMANFAATAN TANAMAN OBAT SEBAGAI UPAYA SWAMEDIKASI DI KELURAHAN TANGKILING KECAMATAN BUKIT BATU KOTA PALANGKA RAYA
}

\section{(UTILIZATION OF DRUG PLANTS AS SWAMEDICATION EFFORTS IN TANGKILING, BUKIT BATU PALANGKA RAYA)}

\author{
Maryani $^{1}$, Ida Ratnasari ${ }^{2}$, Tutwuri Handayani ${ }^{3}$ \\ 1,2,3 Jurusan Perikanan Fakultas Pertanian Universitas Palangka Raya \\ e-mail : maryani@ fish.upr.ac.id
}

\begin{abstract}
Training on the utilization of medicinal plants for residents in Tangkiling Sub-District, Bukit Batu Subdistrict, Palangka Raya is expected to be able to increase knowledge in an effort to self-medication with medicinal plants. The activity is carried out by organizing two types of training related to self-medication using medicinal plants and monitoring the activities carried out. The results of monitoring and evaluation have shown that there has been an increase in consumption of red ginger and turmeric in the family and in activities in the community. The transfer of knowledge about the benefits of the types of family medicinal plants in the surrounding environment and the making of herbal medicine has also taken place from trainees to residents who did not attend the training informally. Medicinal plants that were distributed to the training participants during the service activities were also maintained well in the yard of the house. Overall empowerment activities for residents of Kelurahan Tangkiling, Bukit Batu Subdistrict, Palangka Raya City, Central Kalimantan have been going well.
\end{abstract}

Keywords: herbs, medicinal plants, self-medication

\section{abstrak}

Pelatihan pemanfaatan tanaman obat terhadap warga di Kelurahan Tangkiling Kecamatan Bukit Batu Kota Palangka Raya diharapkan mampu meningkatkan pengetahuan dalam upaya melakukan swamedikasi dengan tanaman obat. Pelaksanaan kegiatan dilakukan dengan menyelenggarakan dua jenis pelatihan yang berkaitan dengan swamedikasi menggunakan tanaman obat dan melakukan pemantauan terhadap kegiatan yang dilakukan. Hasil monitoring dan evaluasi yang telah dilakukan menunjukkan bahwa telah terjadi peningkatan konsumsi wedang jahe merah dan kunyit asam dalam keluarga dan dalam kegiatan-kegiatan di lingkungan warga. Transfer ilmu tentang manfaat jenis-jenis tanaman obat keluarga yang ada di lingkungan sekitar dan pembuatan jamu juga telah terjadi dari peserta pelatihan kepada warga yang tidak mengikuti pelatihan secara informal. Tanaman obat yang dibagikan kepada peserta pelatihan saat kegiatan pengabdian dilakukan juga masih terpelihara dengan baik di pekarangan rumah. Secara keseluruhan kegiatan pemberdayaan pada warga Kelurahan Tangkiling, Kecamatan Bukit Batu Kota Palangka Raya Kalimantan Tengah telah berjalan dengan baik.

Kata kunci: jamu, swamedikasi, tanaman obat

\section{PENDAHULUAN}

Indonesia merupakan negara yang kaya akan sumber daya alam. Diperkirakan hutan Indonesia menyimpan potensi tumbuhan obat sebanyak 30.000 jenis dari total 40.000 jenis tumbuhan dunia. Sebanyak 940 jenis diantaranya telah dinyatakan berkhasiat sebagai obat, atau sekitar $90 \%$ dari seluruh tumbuhan obat yang ada di Benua Asia (Nugroho, 2010). Potensi luar biasa ini dapat digunakan sebagai lahan pengembangan industri herbal medicine dan health food untuk kebutuhan dunia. 
Saat ini, pemanfaatan bahan baku obat herbal oleh masyarakat mencapai kurang lebih 1000 jenis, dimana 74\% diantaranya merupakan tumbuhan liar yang hidup di hutan. Tingkat pemanfaaatan tumbuhan obat masih jauh dari potensi yang ada di alam. Oleh karena itu dengan meningkatnya kebutuhan bahan baku simplisia, dan meluasnya permintaan pasar domestik maupun ekspor, akan meningkatkan pemanfaatan tumbuhan obat yang ada di Indonesia.

Swamedikasi atau pengobatan mandiri adalah kegiatan atau tindakan mengobati diri sendiri dengan obat atau tanpa resep secara tepat dan bertanggung jawab (rasional). Makna swamedikasi adalah bahwa penderita sendiri yang memilih obat tanpa resep untuk mengatasi penyakit yang dideritanya (Djunarko dan Dian, 2011; Winkanda, 2013). Dalam kehidupan sehari-hari, banyak penyakit dan gangguan kesehatan dapat dikenali dan diobati secara mandiri (swamedikasi) baik oleh penderita maupun oleh orang di sekitarnya. Hal ini dianggap lebih hemat waktu dan biaya daripada apabila penderita harus pergi ke dokter. Pengobatan sendiri atau swamedikasi adalah tindakan yang dilakukan untuk mengatasi masalah kesehatan dengan menggunakan obat-obatan yang dapat dikonsumsi tanpa pengawasan dokter atau tindakan yang dilakukan untuk mengatasi masalah kesehatan dengan menggunakan obat-obatan yang dapat dikonsumsi tanpa pengawasan dokter. Obat-obatan yang digunakan untuk swamedikasi biasa disebut dengan obat tanpa resep atau obat bebas atau obat OTC. Obat-obat bebas tersebut dapat diperoleh di toko obat, apotek, supermarket, dan warung-warung dekat rumah (Manan, 2014).

Upaya swamedikasi ini dapat dilakukan berbekal pengetahuan yang cukup tentang cara mengetahui gejala penyakit dan juga pengetahuan tentang khasiat obat. Salah satu jenis bentuk swamedikasi adalah dengan menggunakan obat tradisional yang umumnya mengandung bahan berkhasiat yang berasal dari jenis tumbuhan (Pusat Studi Biofarmaka, 2003). Dalam upaya menggalakkan kembali penggunaan jamu sebagai warisan nenek moyang yang perlu dilestarikan, maka generasi muda saat ini yang sudah kurang mengenal jamu perlu diedukasi kembali.

Tangkiling adalah salah satu Kelurahan di Kecamatan Bukit Batu Kota Palangka Raya Kalimantan Tengah. Kelurahan Tangkiling merupakan daerah subur dan termasuk salah satu daerah penghasil sayur-sayuran untuk Kota Palangka Raya, jika dilihat dari kesuburan tanah di Kelurahan Tangkiling maka Kelurahan Tangkiling dapat dijadikan sebagai sentra penghasil tanaman obat tradisional selain sebagai sentra penghasil sayursayuran.

Tujuan dari kegiatan ini adalah melakukan pembinaan terhadap warga di Kelurahan Tangkiling Kecamatan Bukit Batu Kota Palangaka Raya dengan menyelenggarakan dua jenis pelatihan yang berkaitan dengan swamedikasi menggunakan tanaman obat dan melakukan pemantauan terhadap kegiatan yang dilakukan. Manfaat kegiatan ini adalah meningkatkan keterampilan dan pengetahuan warga Kelurahan Tangkiling dalam mengenal jenis tanaman obat dan cara mengolah tanaman obat yang dapat digunakan untuk swamedikasi di keluarga maupun lingkungan sekitarnya.

\section{METODE PENGABDIAN MASYARAKAT}

Kelompok sasaran dari kegiatan ini adalah warga Kelurahan Tangkiling Kecamatan 
Bukit Batu Kota Palangka Raya. Pelaksanaan kegiatan dilakukan di Bulan April-Mei 2017 di Kelurahan Tangkiling Kecamatan Bukit Batu Kota Palangka Raya. Kegiatan dilaksanakan dalam bentuk pelatihan dan pendampingan dengan beberapa kali tatap muka. Sebagai langkah awal dalam pelaksanaan kegiatan ini maka dilakukan sosialisasi program Ipteks bagi Masyarakat kepada warga Kelurahan Tangkiling Kecamatan Bukit Batu Kota Palangka Raya. Sosialisasi dilakukan dengan melakukan permohonan izin kepada pihak Kelurahan Tangkiling.

\section{Pelatihan Pertama Pengenalan Tanaman Obat.di Lingkungan Sekitar}

Peserta dikenalkan dengan berbagai macam tanaman obat, berlatih mengenal ciri morfologi tanaman, dan bagian-bagian tanaman yang berkhasiat sebagai obat, serta berlatih mengenal tanaman obat dan khasiatnya. Untuk menarik peserta pelatihan, selama pelatihan diberikan dalam bentuk game dan kuis. Media: berbagai jenis tanaman obat dalam bentuk segar (dalam pot), materi slide pengenalan tanaman obat, dan pembagian tanaman obat dan media

\section{Pelatihan Kedua Cara Pemanfaatan Tanaman Obat}

Untuk meningkatkan kecintaan kepada tanaman obat, maka peserta diberikan pelatihan cara meracik tanaman obat menjadi sediaan jamu. Sediaan jamu yang dipraktikkan adalah jamu yang mudah dibuat dan juga umum digunakan untuk meningkatkan kesehatan keluarga, yaitu jamu minuman kunyit asam dan beras kencur. Selain itu, dipraktikkan juga pembuatan jamu beras kencur dalam bentuk sediaan minuman instan. Bahan terdiri dari; 1) Ramuan untuk wedang jahe merah dan, 2) Ramuan untuk kunyit asam.

\section{Evaluasi dan Monitoring}

Evaluasi dan monitoring dilakukan secara berkala dengan mendatangi rumah warga untuk mengetahui sejauh mana pelatihan yang diberikan dapat diimplementasikan, dan memantau tanaman obat yang diberikan kepada masing-masing warga yang hadir pada saat pelatihan masih tetap terpelihara dengan baik di pekarangan rumah.

\section{HASIL DAN PEMBAHASAN}

\section{Pelatihan Pengenalan Tanaman Obat di Lingkungan Sekitar}

Pelatihan pertama yang dilakukan adalah Pelatihan Pengenalan Tanaman Obat Di Lingkungan Sekitar, sebagai narasumber pada materi ini adalah ketua pelaksana pengabdian Ibu Dr. Maryani, S.Pi, M.Si, Kegiatan berjalan lancar diikuti oleh 15 peserta, yang memiliki semangat dan motivasi yang tinggi untuk mendapatkan ilmu dan keterampilan tentang pemanfaatan tanaman obat sebagai swamedikasi. Dalam kegiatan ceramah yang dilakukan, warga dikenalkan dengan berbagai jenis tanaman yang secara empiris dapat berkhasiat obat, selain itu dalam kegiatan ceramah tersebut juga disampaikan bahwa untuk penyembuhan suatu penyakit maka diperlukan dosis pemakaian yang tepat. Selain itu, sekalipun banyak klaim penggunaan tanaman obat lebih aman dibandingkan penggunaan obat kimia, namun dijelaskan juga bahwa tidak sedikit tanaman obat juga dapat menimbulkan efek samping jika penggunaannya tidak tepat (Aziz dan Ghulamahdi, 2001).

Penggunaan bahan alam sebagai obat cenderung mengalami peningkatan dengan adanya isu back tonature dan krisis berkepanjangan yang mengakibatkan turunnya daya 
beli masyarakat terhadap obat-obat modern yang relatif lebih mahal harganya. Obat bahan alam juga dianggap hampir tidak memiliki efek samping yang membahayakan. Pendapat itu belum tentu benar karena untuk mengetahui manfaat dan efek samping obat tersebut secara pasti perlu dilakukan penelitian dan uji praklinis dan uji klinis.

Dalam kegiatan ini, utamanya ibu-ibu dikenalkan terhadap jenis tanaman yang diantaranya sudah banyak dikenal sebagai tanaman hias namun ternyata juga dapat digunakan sebagai tanaman obat serta kelebihan dan kelemahan penggunaan bahan alam sebagai obat. Dan hal yang lebih penting adalah penjelasan lebih rinci tentang kandungan dan khasiat dari ketiga jenis tanaman obat yang telah dibagikan ke peserta pelatihan.

Untuk mengobati penyakit diperlukan waktu lama sehingga penggunaan obat alam lebih tepat, karena efek sampingnya relatif lebih kecil. Di samping keunggulannya, obat bahan alam juga memiliki beberapa kelemahan yang juga merupakan kendala dalam pengembangan obat tradisional antara lain efek farmakologisnya lemah, bahan baku belum terstandar dan bersifat higroskopis, belum dilakukan uji klinik dan mudah tercemar berbagai mikroorganisme (Zein, 2005).

Kunyit merupakan bahan yang sudah terkenal diberbagai negara, banyak digunakan sebagai ramuan jamu karena berkhasiat menyejukkan, membersihkan, menghilangkan gatal, dan menyembuhkan kesemutan. Rimpang tanaman kunyit itu juga bermanfaat sebagai analgetika, antiinflamasi, antioksidan, antimikroba, pencegah kanker, antitumor, dan menurunkan kadar lemak darah dan kolesterol, serta sebagai pembersih darah.

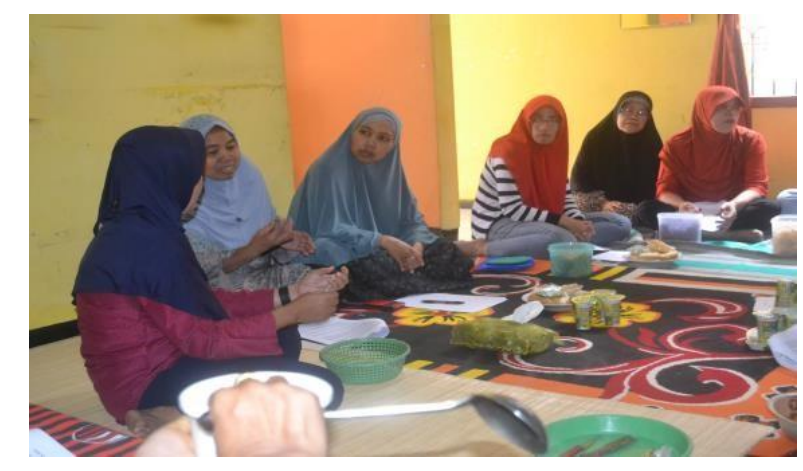

Gambar 1. Kegiatan diskusi dengan peserta

Selain kunyit, kencur dan jahe merah merupakan tanaman obat yang sering digunakan sebagai obat bahan alam. Umumnya, manfaat kencur sering digunakan sebagai obat sakit tenggorokan. Akan tetapi, selain bisa berkhasiat untuk sakit tenggorokan, kencur berfungsi sebagai obat sakit kembung, masuk angin, obat batuk, penambah nafsu makan, disentri, infeksi bakteri, sakit perut, ekspektoran, dll. Minyak atsiri yang dikandung kencur diklaim memiliki banyak senyawa bermanfaat. Senyawa ini berfungsi sebagai zat analgesic, yaitu zat yang memiliki kemampuan untuk mengurangi rasa sakit atau nyeri. Sedangkan jahe merah memiliki salah satu manfaat yang paling terkenal adalah untuk mengobati penyakit asma atau sesak nafas. Menurut pakar herbal, 
jahe merah memiliki khasiat menjaga fungsi saluran pernafasan. Kandungan zat bronki splasmolitika dalam jahe merah terbukti mambu membantu menyerap oksigen dengan baik dan mendukung paru-paru lebih sehat agar reaksi sel maskosit dan eosinofil tidak membahayakan tubuh penderita.

\section{Pelatihan Pembuatan Jamu Tradisional Beras Kencur dan Kunyit Asam}

Untuk meningkatkan kesehatan keluarga, upaya yang dapat dilakukan para ibu dalam keluarga adalah dengan mencegah kejadian sakit (Hariana, 2011). Oleh karena itu, dalam pelatihan ini ibu-ibu diajarkan praktek membuat ramuan jamu yang aman dikonsumsi sehari-hari yang berkhasiat untuk mencegah timbulnya sakit, yaitu jamu beras kencur dan kunyit asam. Kedua ramuan tersebut telah digunakan sejak ratusan tahun lalu di Bumi Pertiwi untuk meningkatkan kebugaran tubuh dan terbukti aman dikonsumsi setiap hari. Upaya mencegah sakit tentu lebih baik dibanding mengobati penyakit yang tentunya akan lebih banyak mengeluarkan biaya. Inilah pentingnya peran ibu dalam keluarga untuk memelihara kesehatan keluarga, sehingga melalui kegiatan ini, jika para ibu mempraktikkan dalam keluarganya diharapkan kejadian sakit dalam keluarga menjadi menurun.

Dalam rangkaian pelatihan pemanfaatan tanaman obat menjadi sediaan jamu untuk meningkatkan kesehatan dengan swamedikasi, terlebih dahulu peserta diberi penjelasan tentang cara pembuatan jamu dengan media presentasi. Untuk materi ini sebagai narasumber adalah praktisi yang berkecimpung di bidang pembuatan jamu tradisional disamping itu kegiatan sehari-harinya para narasumber adalah berdagang jamu tradisional, pada pembuatan jamu wedang jahe merah yang menjadi narasumber adalah Ibu Dwi Rahayu sedang narasumber pembuatan jamu kunyit asam adalah Ibu Tati Misrani. Selain faktor sanitasi dan hygiene, juga disampaikan beberapa ramuan jamu yang dapat dibuat dalam skala rumah tangga.

Sebagian peserta yang sudah berusia lebih dari 50 tahun umumnya sudah tidak begitu asing, dengan pembuatan kunyit asam, dan wedang jahe merah. Namun bagi peserta yang masih berusia di bawah 30 tahun umumnya belum begitu mengenal. Hal ini menunjukkan bahwa budaya minum jamu dan membuat jamu memang sudah mulai berkurang termasuk di Kelurahan Tangkiling. Oleh karena itu, edukasi ini sangat diperlukan untuk melestarikan pembuatan dan pengunaan jamu dalam meningkatkan kesehatan diri sendiri dan keluarga secara mandiri. Penggunaan jamu kunyit asam dan wedang jahe merah utamanya adalah untuk mencegah timbulnya penyakit (Dalimartha, 2003; 2008). Praktik pembuatan jamu juga melibatkan warga sebagai peserta pelatihan seperti terlihat pada gambar.

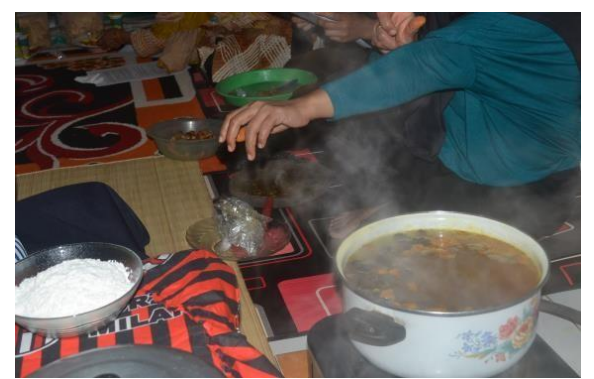

Gambar 2. Kegiatan Praktek Pembuatan Jamu 
Antusiasme warga dalam praktik pembuatan ramuan jamu ini sangat tinggi ditunjukkan dengan pertanyaan-pertanyaan yang diajukan seputar teknis pembuatannya terutama komposisi bahan bakunya. Untuk memudahkan peserta dalam mempraktikannya di rumah, pada pelatihan ini juga kami bagikan materi presentasi yang memuat komposisi bahan-bahan untuk berbagai ramuan jamu yang secara tradisional digunakan untuk memelihara kesehatan keluarga seperti jamu wedang jahe merah dan jamu kunyit asam.

Dari uraian diatas, tampak bahwa kegiatan ini telah memberikan dampak pada warga, yaitu meningkatnya pengetahuan warga akan jenis-jenis tanaman yang berkhasiat sebagai obat yang dapat digunakan untuk swamedikasi bagi keluarganya. Namun demikian, karena menjaga kesehatan atau mencegah sakit tentu lebih penting, maka ramuan tradisional yang dapat dibuat sehari-hari adalah wedangjahe merah dan kunyit asam. Adapun dampak terjadinya peningkatan kesehatan atau menurunnya angka sakit dengan adanya kegiatan ini belum dapat diketahui karena data dari puskesmas belum dapat kami peroleh, namun budaya minum jamu wedang jahe merah dan kunyit asem sebagai upaya swamedikasi semakin meningkat. Selain itu, praktik pembuatan jamu juga telah disebarkan kepada warga lain oleh peserta pelatihan pada warga yang tidak mengikuti pelatihan, yaitu pada kegiatan rutin pertemuan warga di setiap RT. Melalui komunikasi yang berjalan baik antara peneliti dengan mitra, diharapkan budi daya toga dapat terus berlanjut dan menciptakan lingkungan yang asri di wilayah Kelurahan Tangkiling.

\section{PENUTUP}

\section{Simpulan dan Saran}

Kegiatan pemberdayaan yang melibatkan warga Kelurahan Tangkiling Kecamatan Bukit Batu Kota Palangka Raya telah berjalan dengan baik, meliputi kegiatan pelatihan pengenalan tanaman obat, praktik pengolahan tanaman obat menjadi sediaan minuman cair. Melalui kegiatan ini telah terjadi peningkatan pengetahuan dan keterampilan warga terhadap jenis-jenis tanaman yang berkhasiat obat. Selain itu, hasil dari kegiatan ini juga meningkatkan konsumsi ramuan jamu wedang jahe merah dan kunyit asam dalam keluarga sebagai bentuk swamedikasi meningkatkan kebugaran dan mencegah sakit. Perlu dilakukan komunikasi yang berkelanjutan dengan mitra agar kegiatan ini dapat terus berjalan, budi daya tanaman obat terus berkembang dan menyebar untuk warga lain disekitarnya, sehingga dapat meningkatkan penghasilan warga dan hal yang penting adalah pelaksanaan swamedikasi dengan tanaman obat sehingga berdampak pada peningkatan kesehatan tubuh warga.

\section{DAFTAR PUSTAKA}

Aziz SA, Ghulamahdi M. 2001. Standarisasi Teknologi Penyediaan Bahan Tanaman Obat. Bogor (ID): Institut Pertanian Bogor.

Dalimartha S. 2003. Atlas Tumbuhan Obat Indonesia Jilid 3. Jakarta (ID): Puspa Swara.

Dalimartha S. 2008. 1001 Resep Herbal. Jakarta (ID): Penebar Swadaya. 
Dalimartha S. 2008. Atlas Tumbuhan Obat Indonesia Jilid 5. Jakarta (ID): Puspa Swara.

Djunarko dan Dian. 2011. Swamedikasi Yang Baik dan Benar. Intan Sejati. Klaten

Hariana, A. 2011. Tumbuhan Obat dan Khasiatnya.Jakarta: Penebar Swadaya.

Manan, El. 2014. Buku Pintar Swamedikasi (Tips Penanganan Dini Masalah-masalah Kesehatan). Jogjakarta: Saufa.

Nugroho, I.A., 2010, “Lokakarya Nasional Tumbuhan Obat Indonesia. Asian Pacific Forest Genetic Resources Programme Kerjasama Pusat Penelitian dan Pengembangan Peningkatan Produktivitas Hutan", APFORGEN News Letter, 2(2), 1-2

Pusat Studi Biofarmaka. 2003. Panduan Pelatihan Tanaman Obat Tradisional (Swamedikasi): Pengobatan Penyakit Diabetes Mellitus. Bogor (ID): Pusat studi Biofarmaka, Lembaga Penelitian dan Pengabdian kepada Masyarakat, Institut Pertanian Bogor.

Winkanda SP. 2013. Sehat dengan herbal tanpa Dokter. Yogyakarta (ID): Citra Media.

Zein, U. 2005. Pemanfaatan Tumbuhan Obat dalam Upaya Meningkatkan Pemeliharaan Kesehatan. USU Repository. Medan. 